\title{
Analgesic Effect of Intranasal Ketamine for the Management of Post-operative Pain after Strabismus Surgery in Pediatric Patients
}

\author{
Mehdi Sanatkar, Alireza Ebrahim Soltani, Alireza Takzare* \\ Department of Anesthesiology and Critical Care, Farabi Eye Hospital, Tehran University of Medical Sciences, Tehran, IRAN.
}

\begin{abstract}
Background: Strabismus surgery is a common ophthalmic surgical procedure in children. Post-operative pain is an undesirable post-operative outcome in these patients. Objectives: This study aimed to compare the efficacy of intravenous paracetamol and intranasal (IN) ketamine for management of Post-operative pain in children undergoing strabismus surgery. Methods: Sixty pediatric patients who candidate for strabismus surgery were randomized into two groups: IN ketamine (Group K) and IV paracetamol (Group P). Group K received $0.5 \mathrm{mg} / \mathrm{kg}(50 \mathrm{mg} / \mathrm{ml})$ IN ketamine and group $P$ received $10 \mathrm{mg} / \mathrm{kg} \mathrm{IV} \mathrm{paracetamol} \mathrm{after} \mathrm{induction}$ of general anesthesia in all participants. The pain scale, level of sedation, vital signs and adverse effects were recorded at 10,20,30 min and $60 \mathrm{~min}$ post-operative. Results: The mean age of subjects in group $\mathrm{K}$ and group $\mathrm{P}$ was $4.8 \pm 2.6$ and $4.6 \pm 2.5$ years respectively. The comparison of pain score and sedation scale among two groups identified a statistically significant difference between group $K$ and group $P$ at 10, 20, 30 and 60 min after operation. The post-operative adverse events were not statistically significant between both groups. No patients in group $\mathrm{K}$ and 8 cases in group $\mathrm{P}$ needed
\end{abstract}

to additional dose of opioid during recovery stay. Dizziness was seen in four of the patients in group $\mathrm{K}$ and three of the patients in group $\mathrm{P}$. There was no significant difference or changes in terms of vital signs in either group perioperatively. Conclusion: Our study suggested that IN ketamine has been shown to produce more effective analgesia when compared to IV paracetamol after strabismus surgery.

Key words: Strabismus surgery, Paracetamol, Ketamine, Pain scale, Sedation scale.

Correspondence

Dr. Alireza Takzare

Department of Anesthesiology and Critical Care, Farabi Eye Hospital, Tehran University of Medical Sciences, Tehran, IRAN.

Phone: +98938 0379460

Email: ar-takzare@sina.tums.ac.ir

DOI: 10.5530/jyp.2020.12.29

\section{INTRODUCTION}

Pain after strabismus surgery is a common event in pediatric patients but this complication under recognized complaint in Post-operative period and after discharge in these subjects. It is identified that up to $65 \%$ of pediatrics have moderate to severe pain following strabismus surgery. ${ }^{1}$ Post-operative pain is associated with increase hospital stay, parent dissatisfaction and parental contact with the health care after discharge of hospital. ${ }^{2}$ Different agents such as opioids, NSAIDs, steroids and ketamine were administered through intravenous, intramascular, subcutaneous, oral, rectal and intranasal for control of post-operative pain in children. ${ }^{3}$ In many previous studies intravenous paracetamol was used for management of post-operative pain but its use alone does not always produce adequate analgesia. Therefore, anesthesiologists preferred to use other analgesic agents with different mechanism of action. Moreover, placement of a catheter for intravenous administration of analgesics agent in children can increase patients anxiety and pain and is time consuming. Intranasal (IN) delivery of analgesic agents can provides safe, rapid, relief of pain and avoid delay oral administration and provide adequate drug levels with minimal side effects. ${ }^{4}$ IN administration is optimized with absorption of high concentration and low volume agent through the highly vascular surface area of the nasal mucosa. ${ }^{5}$ IN administration of opioid to provide analgesia can be used instead of intravenous opioid in children. ${ }^{6}$ In many previous studies IN fentanyl with bioavailability of $77 \%$ has become more commonly used in prehospital and emergency setting in pediatrics subjects. ${ }^{78}$ It was shown that IN fentanyl is as effective as intravenous morphine to treat moderate to severe pain in children who admitted in emergency department and making that administration of IN fentanyl more commonplace in pediatrics emergency setting. ${ }^{9}$ It was reported in literature that ketamine with sub-dissociative doses can successfully treat post-operative pain. ${ }^{10}$ These studies showed that IN ketamine can readily provide and used as alternative of opioid for management of pain in children in emergency department. The bioavailability of IN ketamine is $45-50 \%$ and with a dose of $1.5 \mathrm{mg} / \mathrm{kg}(50 \mathrm{mg} / \mathrm{ml})$ has been shown to provide an effective analgesia without sedative effect. ${ }^{11,12}$ In this study we aimed to evaluate the efficacy of intravenous paracetamol and IN ketamine for management of post-operative pain in pediatric patients after strabismus surgery.

\section{MATERIALS AND METHODS}

This is prospective, randomized, single blind control trial comparing the effects of IN ketamine with IV paracetamol for management of postoperative pain and sedation in pediatric patients who underwent strabismus surgery. Our study was approved by the local hospital ethical committee. Sixty pediatric patients present to strabismus department with age range of 2 to 8 years, who candidate for strabismus surgery were included in this study and written informed consents by their parents were received. Exclusion criteria included pediatrics whit any abnormality of the nasal anatomy, pathology such as chronic sinusitis, cold and rhinitis, nasal polyposis, septum deviation, atrophic rhinitis, concha hypertrophy, circulatory insufficiency, increased intracranial pressure, allergy to ketamine or paracetamol, inability to provide pain scale assessment and 
Takzare, et al: Analgesic Effect of Intranasal Ketamine for the Management of Postoperative Pain

Table 1: Modified Children's Hospital Ontario Pain Scale (CHEOPS).

\begin{tabular}{cccc}
\hline Score & $\mathbf{0}$ & $\mathbf{1}$ & $\mathbf{2}$ \\
\hline Cry & No cry & Crying, moaning & Scream \\
Facial & Smiling & Neutral & Grimace \\
Verbal & Positive statement & Negative statement & Suffering from pain \\
Torso & Neutral & Variable, upright & Stretched \\
Legs & Neutral & Kicking & Scratched, \\
& & & continuous move \\
\hline
\end{tabular}

case received an analgesic agent immediately before arrival to operating room. Participants were randomized by a computer-generated, random number list and divided to two groups to check for post-operative analgesia and sedation: IN ketamine (Group K) and IV paracetamol (Group P). Anesthesia was induced with 5-8\% sevoflurane and laryngeal mask airway with different size based on patient weight was inserted. Then anesthesia was maintained with $2 \%$ isoflurane and oxygen. Group K received $0.5 \mathrm{mg} / \mathrm{kg}(50 \mathrm{mg} / \mathrm{ml})$ IN ketamine and group $\mathrm{P}$ received $10 \mathrm{mg} / \mathrm{kg} \mathrm{IV} \mathrm{paracetamol} \mathrm{after} \mathrm{induction} \mathrm{in} \mathrm{all} \mathrm{participants.} \mathrm{In} \mathrm{group}$ $\mathrm{K}$ the medication was administered in a protocolized manner discharging approximately half the total dose in each naris. All cases underwent strabismus surgery by one surgeon with duration of operation range of 30 to $45 \mathrm{~min}$. Study investigators recorded post-operative pain score, level of sedation, vital signs and adverse effects at the time of 10, 20, 30 and $60 \mathrm{~min}$ after operation. If patients requested additional analgesic in recovery room, $1 \mu \mathrm{g} / \mathrm{kg}$ fentanyl parenterally administered. Pain scores in our study were evaluated by modified Children's Hospital of Eastern Ontario Pain Scale (CHEOPS) established by McGrath et al..$^{13}$ (Table 1). In this evaluation an experienced observer assessed behavior scoring such as crying, facial impression, verbal complaints and position and movement of the body in post-operative period in all subjects. We assessed the sedative condition in our cases after operation with the Wilson sedation scale (Table 2). The primary outcome measure was comparative reduction of CHEOPS score between group $\mathrm{K}$ and group P 10, 20, 30 and 60 min after operation. Secondary outcome measures were sedation scale score, vital sign and adverse events after operation. Statistical analysis was carried out using the version 13.0 SPSS software for Windows. The data in our study were summarized by using mean (SD) for all normally distributed variables, frequency (percentage) for categorical variables and median with lower and upper ranges for nonnormal continuous variable. We compared two groups by using Student $t$ test and the $\chi^{2}$ test, where appropriate. Pain scores were compared between two groups using a generalized linear model to look at different over time relative to baseline. $P<0.05$ was considered statistically significant. Assuming $80 \%$ power to detect a difference of 2 points on the pain scale with an $\alpha$ of 0.05 , a sample size of 60 cases (30 cases in each group) were established in this study.

\section{RESULTS}

This study included 60 pediatric patients ( 30 cases received IN ketamine and 30 cases received IV paracetamol) who were underwent strabismus surgery in our hospital during February-April 2019. The mean age of subjects in group $\mathrm{K}$ and group $P$ was $4.8 \pm 2.6$ and $4.6 \pm 2.5$ years respectively. Table 3 shows no statistical difference in demographic or clinical characteristics between two groups. The comparison of pain score on the basis of CHEOPS among two groups identified a statistically significant difference between group $\mathrm{K}$ and group $\mathrm{P}$ at 10, 20, 30 and 60 min after operation (Table 4) (Figure 1).
Table 2: Wilson sedation scale.

\begin{tabular}{cc}
\hline Score & Degree of sedation \\
\hline 1 & Fully awake, oriented \\
2 & Lethargic \\
3 & Open eye with verbal stimulus \\
4 & Open eye with moderate pain \\
5 & Dose not respond moderate pain \\
\hline
\end{tabular}

Table 3: The comparison of demographic and clinical characteristics in both groups.

\begin{tabular}{lccc}
\hline \multicolumn{1}{c}{ Characteristics } & Group K & Group P & $P$-value \\
\hline Age (yrs) & $4.8 \pm 2.6$ & $4.6 \pm 2.5$ & 0.64 \\
Sex (male) & 18 & 16 & 0.24 \\
Weight (Kg) & $18.6 \pm 4.8$ & $17.8 \pm 5.6$ & 0.67 \\
$\begin{array}{l}\text { Baseline heart rate (beats/min) } \\
\text { Baseline Respiratory rate (breathe/ }\end{array}$ & $108 \pm 14$ & $110 \pm 12$ & 0.34 \\
min) & $18.6 \pm 4.2$ & $17.9 \pm 4.4$ & 0.98 \\
$\begin{array}{l}\text { Baseline systolic blood pressure } \\
\text { (mm Hg) }\end{array}$ & $101.2 \pm 10.4$ & $100.8 \pm 11.2$ & 0.48 \\
$\begin{array}{l}\text { Baseline diastolic blood pressure } \\
\text { (mm Hg) }\end{array}$ & $62.2 \pm 5.4$ & $62.8 \pm 6.8$ & 0.24 \\
$\begin{array}{l}\text { Operation duration (min) } \\
\text { Anesthesia duration (min) }\end{array}$ & $32.1 \pm 8.6$ & $33.4 \pm 6.4$ & 0.74 \\
\hline
\end{tabular}

Table 4: Modified Children's Hospital Ontario Pain Scale (CHEOPS) results groups.

\begin{tabular}{cccc}
\hline Pain score & Group K & Group P & P-value \\
\hline 10 min postoperation $($ Mean \pm SD) & $1.4 \pm 0.6$ & $2.8 \pm 1.2$ & $<0.001$ \\
20 min postoperation $($ Mean \pm SD) & $1.2 \pm 0.8$ & $2.4 \pm 1.1$ & $<0.001$ \\
30 min postoperation $($ Mean \pm SD) & $1.1 \pm 0.4$ & $2.3 \pm 1.0$ & $<0.001$ \\
60 min postoperation $($ Mean \pm SD) & $0.9 \pm 0.6$ & $2.1 \pm 0.9$ & $<0.001$ \\
\hline
\end{tabular}

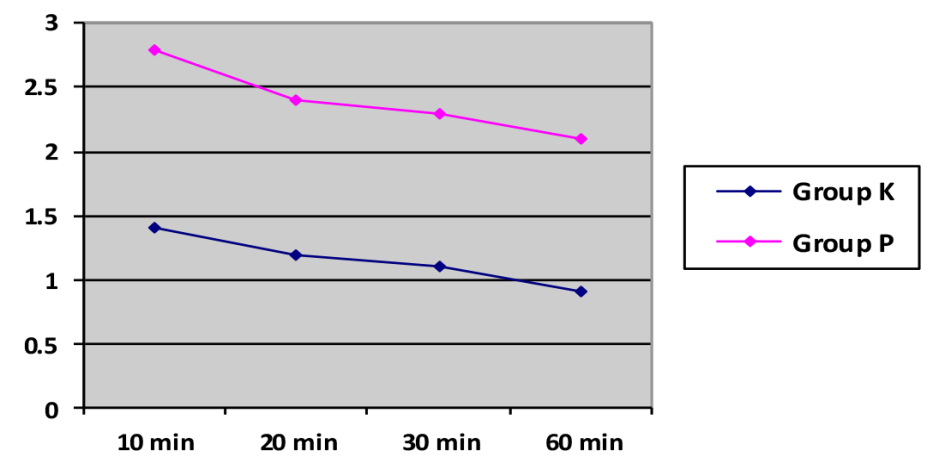

Figure 1: Comparison of postoperative pain management of both groups.

The comparison of sedation scale on the basis of Wilson scale, there was a statistically significant difference in group $\mathrm{K}$ compared to group $\mathrm{P}$ at 10, 20, 30 and $60 \mathrm{~min}$ after operation (Table 5) (Figure 2).

No patients in group $\mathrm{K}$ and 8 cases in group $\mathrm{P}$ needed to additional dose of opioid during recovery stay. The post-operative adverse events were not statistically significant between both groups. The most common adverse events were dizziness and nausea and vomiting. Dizziness was 
Table 5: Wilson sedation scale results groups.

\begin{tabular}{cccc}
\hline Sedation score & Group K & Group P & P-value \\
\hline 10 min postoperation $($ Mean \pm SD) & $2.4 \pm 0.4$ & $1.1 \pm 0.2$ & 0.02 \\
20 min postoperation $($ Mean \pm SD) & $2.6 \pm 0.2$ & $1.0 \pm 0.3$ & 0.04 \\
30 min postoperation $($ Mean \pm SD) & $2.8 \pm 0.3$ & $1.0 \pm 0.1$ & 0.04 \\
60 min postoperation $($ Mean \pm SD) & $2.8 \pm 0.4$ & $0.9 \pm 0.3$ & 0.03 \\
\hline
\end{tabular}

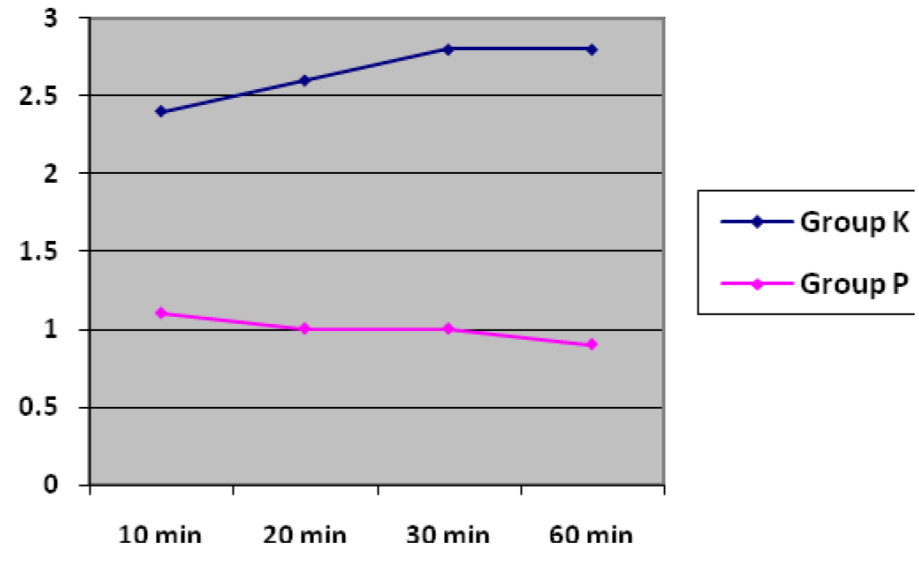

Figure 2: Comparison of postoperative sedation score of both groups.

seen in four of the patients in group $\mathrm{K}$ and three of the patients in group $\mathrm{P}(p=0.84)$. Moreover, the nausea and vomiting were seen in three and two in group $\mathrm{k}$ and group $\mathrm{P}$ respectively $(p=0.94)$. In addition, there was no significant difference or changes in terms of vital signs in either group perioperatively.

\section{DISCUSSION}

Management of pain immediately post-operative period in pediatrics patients enhance patient comfort and facilitate recovery in these subjects. The most effective pain control should be administered in the early post-operative period and achieved with a multimodal approach including acetaminophen, NSAID and opioid agents in pediatric patients. $^{2}$ Despite use of these combinations after strabismus surgery, many children stillexperience moderate to severe pain and anesthesiologist often treat this complication with short acting narcotics such as fentanyl in the recovery room. Opioids provide potent analgesia but may associate with respiratory depression, post-operative nausea and vomiting anddrowsinessin pediatricssubjects. Oneofthemostcommonmedications for management of post-operative pain is paracetamol, but its use alone does not always produce adequate analgesia. NSAID provides effective analgesia but the potency of these agents is lower than opioids. IN fentanyl due to its high potency and lipophilicity can act as short as $7 \mathrm{~min}$ and has bioavailability of $77 \%$. IN fentanyl has been shown that to be an effective and well tolerated analgesic agent in management of post-operative pain in pediatrics patients. ${ }^{7,14}$ Ketamine is widely used for analgesia and sedation in pediatric patients and published studies has reported its efficacy when administered through IN route for decades. Ketamine is a NMDA receptor antagonist and binds to the receptor on the spinal cord and brain and present an analgesic effect. ${ }^{15}$ There are many previous studies that identified the efficacy of ketamine for management of acute post-operative pain. ${ }^{16,17}$ Moreover, it was shown that administration of ketamine intravenously, intramascularly, rectally, subcutaneously and orally can be an effective pain reliever without adverse effect in pediatric patients after operation. ${ }^{2,18,19}$ It was identified that IN ketamine reached the maximum analgesic effect approximately 3 to $4 \mathrm{~min}$ after administration..$^{20}$ Diaz et al. found that IN ketamine could improve cooperation of childrenbeforeoperationversusplacebo. ${ }^{21}$ It wasestablished thatketaminetobeanimportantagentfor post-operativepain management in adult and pediatrics patients. ${ }^{22}$ In a study conducted in 2013 , it was shown that IN ketamine with dose of $1 \mathrm{mg} / \mathrm{kg}$ provided significant analgesic effect in pediatrics subjects with limb surgery. ${ }^{10}$ In this study the most adverse events of IN ketamine administration were dizziness and poor taste. Another study that performed about post-operative pain relive with IN ketamine showed that the median dose of ketamine that required for significant pain management was $0.98 \mathrm{mg} / \mathrm{kg} .{ }^{23} \mathrm{In}$ a clinical trial that compared IN ketamine with IN fentanyl for management of pain of injury in pediatrics reported that no clinical and statistical difference between medications. ${ }^{24}$ In a another prospective, double blind study that compared analgesic efficacy of IN ketamine $(1 \mathrm{mg} / \mathrm{kg})$ and IN fentanyl $(1.5 \mu \mathrm{g} / \mathrm{kg})$ in a pediatric population, suggested that IN ketamine was found to be as effective as IN fentanyl in relieving pain after administration. Moreover, in this study no patients in either group experienced adverse effects, but a higher level of sedation recorded in ketamine group. ${ }^{25}$ Yenigun et al. in a study that IN ketamine administered for post-operative analgesia in pediatric patients after adenotonsillectomy was statistically more effective than IV paracetamol. ${ }^{26-28}$ In our study, the analgesic effects of IN ketamine compared with IV paracetamol for pain management of pediatrics who underwent strabismus surgery. We found that IN ketamine administered for post-operative pain relieve after strabismus surgery was statistically more effective than IV paracetamol at all times from post- $10 \mathrm{~min}$ to post-60 $\mathrm{min}$ after operation. In our study IN ketamine administration was associated with greater rates of sedation but this level of sedation was complications free and did not prolonged recovery and hospital stay. Therefore, low dose of IN ketamine $(0.5 \mathrm{mg} / \mathrm{kg})$ is an optimal dose of ketamine to provide effective analgesia while minimizing sedation. In our study the incidence of nausea, vomiting and respiratory depression in ketamine group was similar to paracetamol group. There were several limitations to our study and included a small sample, therefore, additional studies with larger samples are needed to confirm our findings. We concluded that low dose of IN ketamine administration may create a safe and effective approach with ease of administration and rapid action and produced reliable analgesia for post-operative pain management in pediatrics subjects. Our study suggested that IN ketamine has been shown to produce more effective analgesia when compared to IV paracetamol after strabismus surgery. However, IN ketamine administration was associated with greater rates of sedation. We think IN ketamine with dose of $0.5 \mathrm{mg} / \mathrm{kg}$ is an optimal dose of ketamine to provide effective analgesia while minimizing sedation in children who underwent strabismus surgery.

\section{ACKNOWLEDGEMENT}

This research has been supported by Tehran University of Medical Sciences and Health Service Grant.

\section{CONFLICT OF INTEREST}

The authors declare that they have no conflict of interest.

\section{ABBREVIATIONS}

IN: Intranasal; IV: Intravenous; CHEOPS: Children's Hospital of Eastern Ontario Pain Scale.

\section{REFERENCES}

1. Enyedi LB, Wallace DK, DeDear GL. A double-masked randomized trial of postoperative local anesthetic for pain control in pediatric strabismus surgery. J AAPOS. 2017;21(2):107-11.

2. Yenigun A, Et T, Aytac S, Olcay B. Comparison of different administration of 
ketamine and intravenous tramadol hydrochloride for post-operative pain relief and sedation after pediatric tonsillectomy. J Craniofac Surg. 2015;26(1):e21-4

3. Umuroglu T, Eti Z, Ciftçi H, Yilmaz GF. Analgesia for adenotonsillectomy in children: A comparison of morphine, ketamine and tramadol. Paediatr Anaesth. 2004:14(7):568-73.

4. Gausche-Hill M, Brown KM, Oliver ZJ, Sasson C, Dayan PS, Eschmann NM, et al. An Evidence-based Guideline for prehospital analgesia in trauma. Prehosp Emerg Care. 2014;18(Suppl 1):25-34.

5. Grassin-Delyle S, Buenestado A, Naline E, Faisy C, Blouquit-Laye S, Couderc LJ, et al. Intranasal drug delivery: An efficient and non-invasive route for systemic administration: Focus on opioids. Pharmacol Ther. 2012;134(3):366-79.

6. Prommer $\mathrm{E}$, Thompson L. Intranasal fentanyl for pain control: Current status with a focus on patient considerations. Patient Prefer Adherence. 2011;5:157-64.

7. Mudd S. Intranasal fentanyl for pain management in children: A systematic review of the literature. J Pediatr Health Care. 2011;25(5):316-22.

8. Panagiotou I, Mystakidou K. Intranasal fentanyl: from pharmacokinetics and bioavailability to current treatment applications. Expert Rev Anticancer Ther. 2010;10(7):1009-21.

9. Rickard C, O'Meara P, McGrail M, Garner D, McLean A, LeLievre P. A randomized controlled trial of intranasal fentanyl vs intravenous morphine for analgesia in the prehospital setting. Am J Emerg Med. 2007;25(8):911-7.

10. Yeaman F, Oakley E, Meek R, Graudins A. Sub-dissociative dose intranasal ketamine for limb injury pain in children in the emergency department: A pilot study. Emerg Med Australas. 2013;25(2):161-7.

11. Malinovsky JM, Servin F, Cozian A, Lepage JY, Pinaud M. Ketamine and norketamine plasma concentrations after i.v., nasal and rectal administration in children. Br J Anaesth. 1996;77(2):203-7.

12. Yanagihara Y, Ohtani M, Kariya S, Uchino K, Hiraishi T, Ashizawa N, et al. Plasma concentration profiles of ketamine and norketamine after administration of various ketamine preparations to healthy Japanese volunteers. Biopharm Drug Dispos. 2003;24(1):37-43

13. Ishizaki $Y$, et al. Japanese clinical guidelines for chronic pain in children and adolescents. Pediatrics International. 2012;54(1):1-7.

14. Hansen MS, Dahl JB. Limited evidence for intranasal fentanyl in the emergency department and the prehospital setting: A systematic review. Dan Med J. 2013;60(1):A4563

15. Aydin ON, Ugur B, Ozgun S, Eyigör H, Copcu O. Pain prevention with intraoperative ketamine in outpatient children undergoing tonsillectomy or tonsillectomy and adenotomy. J Clin Anesth. 2007;19(2):115-9.

16. Laskowski K, Stirling A, McKay WP, Lim HJ. A systematic review of intravenous ketamine for post-operative analgesia. Can J Anaesth. 2011;58(10):911-23.

17. Espahbodi $E$, Sanatkar $M$, Sadrossadat $H$, Darabi VME, Azarshahin $M$, Shoroughi M. Ketamine or atropine: which one better prevents oculocardiac reflex during eye surgery? A prospective randomized clinical trial. Acta Med Iran. 2015;53(3):158-61.

18. Moezi L, Shafaroodi H, Sarkar S, Emami-Razavi SH, Sanatkar M, Mirazi N, et al. Involvement of nitrergic and opioidergic systems in the hypothermia induced by cholestasis in rats. Pathophysiology. 2006;13(4):227-32.

19. Hashemian F, Farahani F, Sanatkar M. Changes in growth pattern after adenotonsillectomy in children under 12 years old. Acta Med Iran. 2010;48(5):316-9

20. Riediger C, Haschke M, Bitter C, Fabbro T, Schaeren S, Urwyler A, et al. The analgesic effect of combined treatment with intranasal S-ketamine and intranasal midazolam compared with morphine patient-controlled analgesia in spinal surgery patients: A pilot study. J Pain Res. 2015;8:87-94.

21. Diaz JH. Intranasal ketamine preinduction of paediatric outpatients. Paediatr Anaesth. 1997;7(4):273-8.

22. Yeaman F, Meek R, Egerton-Warburton D, Rosengarten $P$, Graudins A. Subdissociative-dose intranasal ketamine for moderate to severe pain in adult emergency department patients. Emerg Med Australas. 2014;26(3):237-42.

23. Borland M, Milsom S, Esson A. Equivalency of two concentrations of fentanyl administered by the intranasal route for acute analgesia in children in a paediatric emergency department: A randomized controlled trial. Emerg Med Australas. $2011 ; 23(2): 202-8$

24. Graudins A, Meek R, Egerton-Warburton D, Oakley E, Seith R. The PICHFORK (Pain in Children Fentanyl or Ketamine) trial: A randomized controlled tria comparing intranasal ketamine and fentanyl for the relief of moderate to severe pain in children with limb injuries. Ann Emerg Med. 2015;65(3):248-54.

25. Quinn K, Kriss S, Drapkin J, Likourezos A, Pushkar I, Brady J, et al. Analgesic Efficacy of Intranasal Ketamine Versus Intranasal Fentanyl for Moderate to Severe Pain in Children: A Prospective, Randomized, Double-Blind Study. Pediatr Emerg Care. 2018

26. Yenigun A, Yilmaz S, Dogan R, Goktas SS, Calim M, Ozturan O. Demonstration of analgesic effect of intranasal ketamine and intranasal fentanyl for post-operative pain after pediatric tonsillectomy. Int J Pediatr Otorhinolaryngol. 2018;104:182-5.

27. Poonai N, Canton K, Ali S, Hendrikx S, Shah A, Miller M, et al. Intranasa ketamine for anesthetic premedication in children: A systematic review. Pain Manag. 2018;8(6):495-503.

28. FreyTM, Florin TA, Caruso M, Zhang N, Zhang Y, Mittiga MR. Effect of Intranasal Ketamine vs Fentanyl on Pain Reduction for Extremity Injuries in Children: The PRIME Randomized Clinical Trial. JAMA Pediatr. 2019;173(2):140-6.

Article History: Submission Date : 03-03-2020; Revised Date : 17-03-2020; Acceptance Date : 06-04-2020.

Cite this article: Sanatkar M, Soltani AE, Takzare A. The Analgesic Effect of Intranasal Ketamine for Management of Postoperative Pain after Strabismus Surgery in Pediatric Patients. J Young Pharm. 2020;12(2):145-8. 